\title{
IN-VITRO REGENERATION AND DEVELOPMENT FOR THE CONSERVATION AND PROPAGATION OF TOMATO PLANT (SOLANUM LYCOPERSICUM) AND CURRANT TOMATO (S. PIMPINELLIFOLIUM) FROM TWO DIFFERENT EXPLANTS
}

\author{
RAZA, M. A. ${ }^{1,2}$-NAWAZ, A. ${ }^{2}-$ ALI, M. ${ }^{1}-$ ZAYNAB, M. ${ }^{3}$ - MUNTHA, S. T. ${ }^{4}-$ ZAIDI, S. H. R. ${ }^{5}-$ \\ KHAN, A. R. ${ }^{5}-$ ZHENG, X.-L. ${ }^{*}$ \\ ${ }^{1}$ College of Food Science and Biotechnology, Key Laboratory of Fruits and Vegetables \\ Postharvest and Processing Technology Research of Zhejiang Province, Zhejiang Gongshang \\ University, Hangzhou 310018, PR China
}

${ }^{2}$ Department of Horticulture, Faculty of Agricultural Sciences and Technology, Bahauddin Zakariya University, Multan 60000, Pakistan

${ }^{3}$ College of Life Sciences and Oceanography, Shenzhen University, Shenzhen 518060, PR China

${ }^{4}$ Laboratory of Germplasm Innovation and Molecular Breeding, Institute of Vegetable Sciences, Zhejiang University, Hangzhou 310058, PR China

${ }^{5}$ Zhejiang Key Laboratory of Crop Germplasm, Department of Agronomy, College of Agriculture and Biotechnology, Zhejiang University, Hangzhou 310058, PR China

\author{
*Corresponding author \\ zheng9393@163.com (Zheng, X.-L.) \\ (Received 12 $2^{\text {th }}$ Jul 2019; accepted 29 ${ }^{\text {th }}$ Nov 2019)
}

\begin{abstract}
While the contribution of stable tomato cultivars to ecological balance and environmental preservation has been recognized, two tomato cultivars have developed methods for tissue culture. For two tomato cultivars Solanum lycopersicum and Solanum pimpinellifolium, the regeneration capacity of two types of explants (cotyledons and stem node segments) was compared. Explants were cultured on five different regeneration media ( $1 / 2 \mathrm{MS}$ and $\mathrm{BAP})$ for stem node and MS for callus induction with a combination of 6benzylaminopurine (BAP) and $\alpha$ - naphthaleneacetic acid (NAA). It was found that ability to regenerate was substantially dependent on both the cultivars and the type of explant. Stem nodes, followed by cotyledons, were the best explants to induce shoot regeneration. It was noticed that the best formulation of the medium for this regeneration from cotyledon explants used was MS with $1 \mathrm{mg} / \mathrm{L}$ BAP and MS+1BAP+0.25 NAA mg/L for callus induction in S. pimpinellifolium and for stem node explant the best formulation used was $1 / 2 \mathrm{MS}$ and 7 $\mathrm{mg} / \mathrm{L}$ BAP in S. lycopersicum was observed. All these data raised the possibility that to preserve and propagate wide hybrids of tomato materials in vitro, the regeneration ability of two explants was compared in Solanum lycopersicum and S. pimpinellifolium.
\end{abstract}

Keywords: tomato, explants, benzyloaminopurine (BAP), $\alpha$-naphthylacetic acid (NAA), stem node

\section{Introduction}

Tomato (Solanum lycopersicum, $2 \mathrm{n}=2 \mathrm{x}=24$ ), is an economically important crop worldwide. Moreover, this vegetable appears as a model plant for the introgression of agronomically crucial genes into the genome of dicotyledonous crop plants (Bhatia et al., 2004). The introduction of qualitative traits into commercial tomato cultivars is substantial, the aim being to ameliorate their nutritional value, productivity, abiotic stress resistance and application in molecular farming (Gerszberg et al., 2015). These crop species exhibited 
extraordinary nutritional value that's why it is considered to be preventive food (Raiola et al., 2014).

Recently, this crop has gained huge popularity due to its anti-cancer and antioxidant characteristic (Khuong et al., 2013). Elaboration of the aforementioned system is essential for positive results in a broad range of techniques, including micro propagation, mutation selection, somatic hybridization or germplasm preservation of the ecological balance (Benson, 2000).

Numerous studies pointed out that the process of tomato regeneration via the organogenesis pathway is influenced by various elements, including media composition, environmental conditions, genotype, explant origin and its age (Ishag et al., 2009; Rashid and Bal, 2010; Zhang et al., 2012; Wayase and Shitole, 2014). So far, several procedures were developed concerning in vitro tomato plants regeneration from diverse explants through organogenesis and tomato transformation (Gerszberg et al., 2015).

These findings pointed out the intractability of $S$. lycopersicum explants (fragmentary or even complete incapability to react to in vitro culture impulses) (Bhatia et al., 2004). Consequently, the improvement of a suitable recovery system exploiting tissue culture techniques of $S$. lycopersicum plants has a great potential if we consider the fact that various genotypes differ in regards to their morphogenic potential.

Traditional methods for tomato breeding can be expensive and tedious due to the time and facilities required by each breeding generation and to the problems with the selection of suitable standards for cultivating (Gerszberg et al., 2015). Therefore, as an alternative, the creation of effective regeneration protocols is an essential step for exploiting of tissue or cell culture for genetic amelioration.

Tomato in vitro culture has been used successfully in various biotechnological applications including clonal propagation of high-value commercial cultivars, virus-free plants, and genetic transformation (Hanus-Fajerska, 2005; Li et al., 2011; Yarra et al., 2012; Namitha and Pradeep, 2013).

The current research was focused on the impact of different media formulations on the regeneration of two tomato inbred lines of $S$. lycopersicum and $S$. pimpinellifolium. We used two inbred lines for in vitro culture to establish the best system of tissue culture in tomato, to conserve $\mathrm{F}_{1}$ plants from wide hybridization for the balance of ecology.

\section{Materials and methods}

\section{Plant materials}

The present research work was conducted at Department of Horticulture, Faculty of Agricultural Sciences and Technology, Bahauddin Zakariya University Multan, Pakistan. Two different inbred lines of Solanum lycopersicum cv. Micro-Tom $(2 n=24)$ and S. pimpinellifolium line WVa700 $(2 \mathrm{n}=24)$ were used as a plant material in this study. The seeds of these varieties were surface sterilized with $70 \%(\mathrm{v} / \mathrm{v})$ ethanol for 1 minute; subsequently they were dipped in a commercial bleach solution comprising $5.5 \%(\mathrm{w} / \mathrm{v})$ of sodium hypochlorite for 10 minutes accompanied by 5 times rinsed with sterilized distilled water (3 minutes for each).

\section{Culture conditions}

The seeds were placed in a sterilized glass jar containing MS medium and then transferred to the growth room under controlled conditions at a temperature of $25 \pm 1^{\circ} \mathrm{C}$ 
under 16 hours of photoperiod light intensity (1500 lux) and relative humidity (60$70 \%$ ). Sterilized seeds were placed in jars on the seed germination medium. Four seeds were inoculated in each jar. The culture was then incubated in the incubation room until seed germination. It was observed that seeds began to grow in the dark and were later transferred to light.

The explants, both cotyledon and stem node, were taken from sterile seedlings (young seedlings) and placed on two media types: MS with different concentrations of benzylaminopurine (BAP i.e. cytokinin) and $\alpha$ - naphthaleneacetic acid (NAA i.e. auxin) for callus induction and $1 / 2 \mathrm{MS}$ and BAP with different concentrations for stem node induction respectively to conserve $\mathrm{F}_{1}$ plants as shown in (Table 1 and Table 2). Experiment was repeated three times, with a total of 150 explants (50 explants per replicate).

Table 1. Composition of culture media used for stem node induction and plant regeneration of Solanum lycopersicum and Solanum pimpinellifolium

\begin{tabular}{c|c}
\hline Medium & Composition \\
\hline $\mathrm{MS}_{1}$ & without plant growth regulators \\
$\mathrm{MS}_{2}$ & $1 / 2 \mathrm{MS}+1 \mathrm{mg} / \mathrm{L}$ BAP \\
$\mathrm{MS}_{3}$ & $1 / 2 \mathrm{MS}+3 \mathrm{mg} / \mathrm{L} \mathrm{BAP}$ \\
$\mathrm{MS}_{4}$ & $1 / 2 \mathrm{MS}+5 \mathrm{mg} / \mathrm{L} \mathrm{BAP}$ \\
$\mathrm{MS}_{5}$ & $1 / 2 \mathrm{MS}+7 \mathrm{mg} / \mathrm{L} \mathrm{BAP}$ \\
\hline
\end{tabular}

MS= Murashige and Skoog medium, $\mathrm{BAP}=$ benzyloaminopurine

Table 2. Composition of culture media used for callus induction and plant regeneration of Solanum lycopersicum and Solanum pimpinellifolium

\begin{tabular}{c|c}
\hline Medium & Composition \\
\hline $\mathrm{MS}_{1}$ & without phytohormones \\
$\mathrm{MS}_{2}$ & $1 \mathrm{mg} / \mathrm{L} \mathrm{BAP}+0.25 \mathrm{mg} / \mathrm{L} \mathrm{NAA}$ \\
$\mathrm{MS}_{3}$ & $1 \mathrm{mg} / \mathrm{L} \mathrm{BAP}+0.50 \mathrm{mg} / \mathrm{L} \mathrm{NAA}$ \\
$\mathrm{MS}_{4}$ & $2 \mathrm{mg} / \mathrm{L} \mathrm{BAP}+0.25 \mathrm{mg} / \mathrm{L} \mathrm{NAA}$ \\
$\mathrm{MS}_{5}$ & $2 \mathrm{mg} / \mathrm{L} \mathrm{BAP}+0.50 \mathrm{mg} / \mathrm{L} \mathrm{NAA}$ \\
\hline
\end{tabular}

$\mathrm{BAP}=$ benzyloaminopurine, $\mathrm{NAA}=\alpha-$ naphthaleneacetic acid

Experimental data for stem node induction and callus bud induction was collected after 15, 30 and 45 days, respectively. All the regeneration parameters (e.g. callus bud induction frequency and axillary bud frequency or growth features) were evaluated constantly. Explants of the two varieties were grown on 5 different media to evaluate their regeneration capacity.

\section{Statistical analysis}

The data collected was statistically analyzed following the analysis of the variance (ANOVA) technique and the mean differences were assessed by Duncan's Multiple Range Test (DMRT) using the statistical computer package program MSTATC (Gomez and Gomez, 1984). 


\section{Results}

The purpose of this study was to investigate the performance of the two tomato explants, one explant (cotyledon) for callus induction and another explant (stem node) for axillary bud induction from two different cultivars i.e. inbred lines of $S$. lycopersicum cv. (Micro-Tom) ( $2 \mathrm{n}$ $=24)$ and $S$. pimpinellifolium line $(\mathrm{WVa700})(2 \mathrm{n}=24)$ were used as parents. The seed germination rate on MS media was $80 \%$ where $1.5 \%$ of the seeds were contaminated and the remainder was unable to grow. The impact of different levels and combinations of PGRs in both cultivars was noted in MS and $1 / 2$ MS media for tomato explant for callus proliferation and stem node induction.

In the present experiment, the capability of two types of tomato explants (cotyledons and stem nodes) for the regeneration through indirect organogenesis was tested. Both explants cut from tomato seedlings (young seedlings) were cultured on various media: $1 / 2 \mathrm{MS}+\mathrm{BAP}$ (at different concentrations) for stem node and BAP (cytokinin), together with NAA (auxin) (at different concentrations) for cotyledon for the production of callus and multiple shoots (Table 1 and Table 2).

Generally, callus induction was noticed in the aforementioned type of explant culture. Among the 5 media tested, no substantial variation was observed in the frequency of callus induction except S.pimpinelifolium at BAP, together with NAA (at different concentrations) for cotyledon for the production of callus but the highest callus bud induction frequency was noticed with the concentration of MS+ 1BAP+0.25 NAA (Fig. 1).

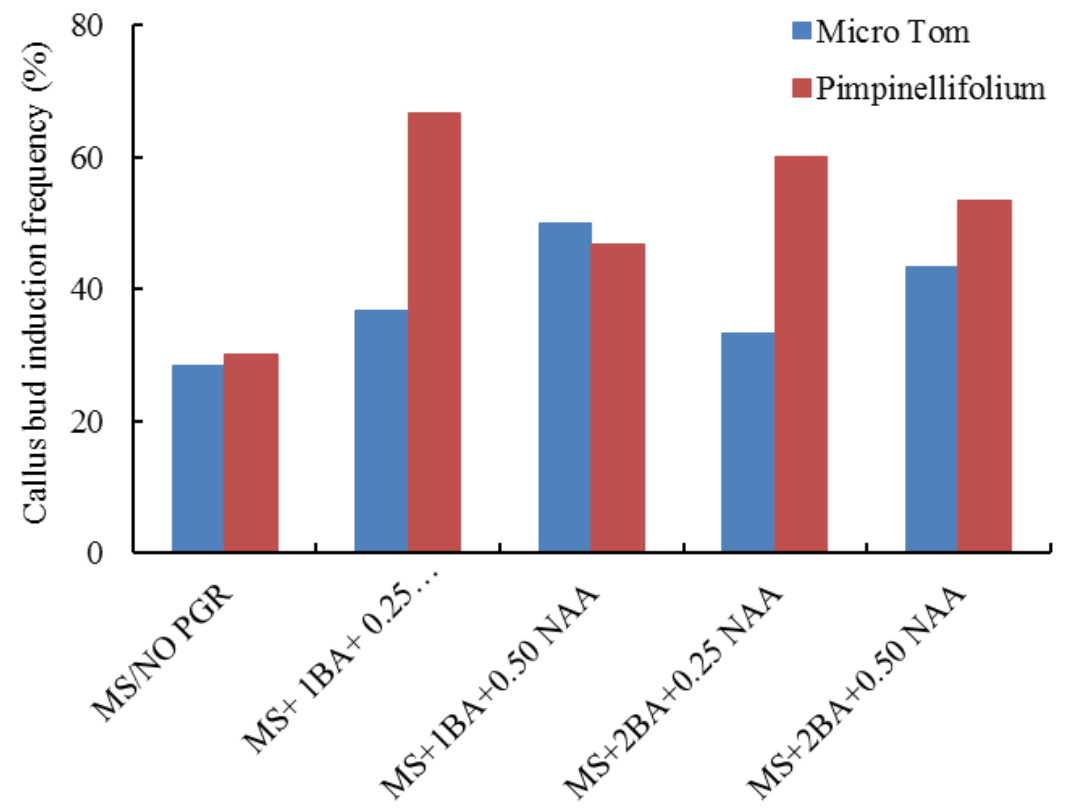

Figure 1. Callus bud induction frequency of Solanum lycopersicum cv. Micro-Tom and S. pimpinellifolium line WVa700

Callus formation began within $\sim 12$ days and shortly thereafter buds occurred. The origination of calli and shoots was noticed in the middle part of explants and on cut edges. In terms of morphology, the callus was fragile and characterized by a pale yellow or green color. In general, stem node explant showed high frequency of axillary bud regeneration in comparison to the callus originating from cotyledons because callus 
induction took a long time to regenerate while stem node usually took less time. Shoot regeneration frequency changed with medium composition, the variety and also with explant type.

Despite the fact the plant regeneration could be caused with BAP only, combining with NAA enhanced the frequency of plant regeneration significantly. Based on our results, MS with $1 \mathrm{mg} / \mathrm{L}$ BAP and $0.25 \mathrm{mg} / \mathrm{L} \mathrm{NAA}$ is the best formulation of the medium for regeneration from the cotyledon explants used in this research. The regeneration of plants from axillary buds or shoots has been shown to be the most generally applicable and reliable method of in vitro true-to-type propagation (Fig. 2).

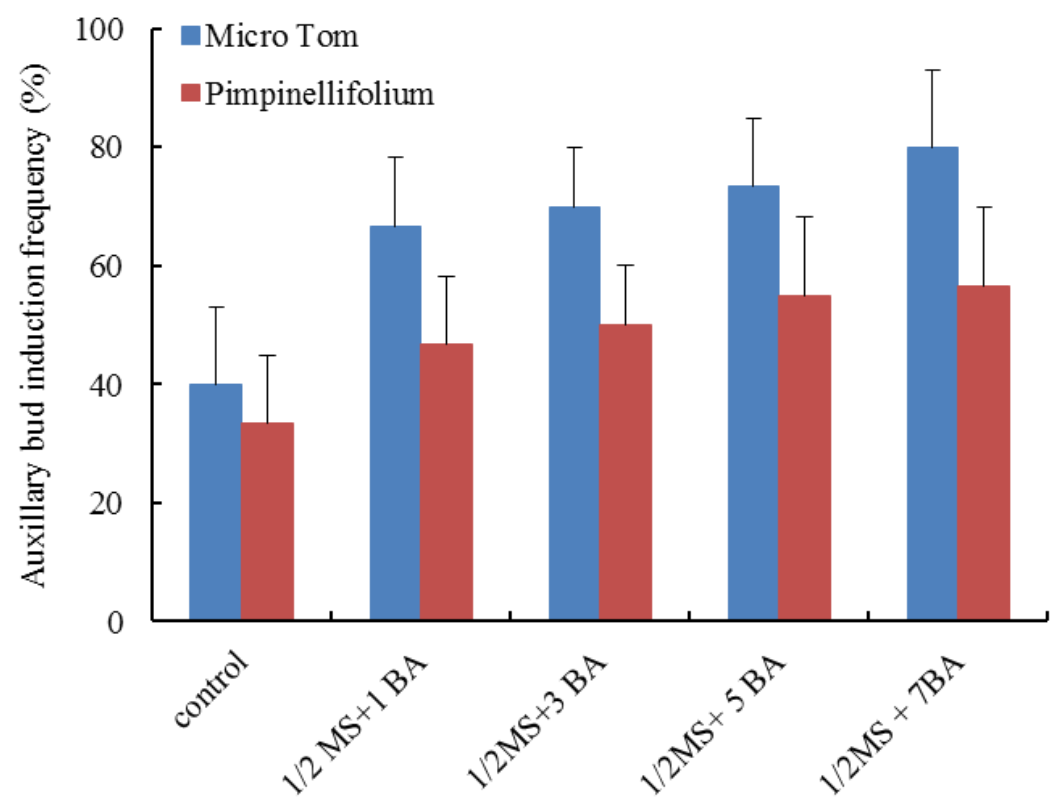

Figure 2. Axillary bud formation percentage of Solanum lycopersicum cv. Micro-Tom and S. pimpinellifolium line WVa700

We observed high regeneration axillary bud frequency from the stem node explants used in this study with the following concentrations $1 / 2 \mathrm{MS}$ and $1 \mathrm{BA}, 1 / 2 \mathrm{MS}$ and 3BA, $1 / 2 \mathrm{MS}$ and $5 \mathrm{BA}$ and $1 / 2 \mathrm{MS}$ and $7 \mathrm{BA}$.

Our data showed the highest axillary bud regeneration frequency (80\%) in S. lycopersicum (Micro-Tom) and (56.6\%) in S. pimpinelifolium (WVa700). Moreover, by comparing two cultivars, highest germination rate was observed in Micro-Tom and lower in Pimpinellifolium (WVa700). It has therefore been noted that $1 / 2 \mathrm{MS}$ and $7 \mathrm{mg} / \mathrm{L}$ BA in Micro-Tom are the best formulation of the medium used for this stem node explant regeneration (S.lycopersicum) (Fig. 2).

According to recent findings, in callus induction, S. pimpinellifolium (WVa700) showed high callus bud induction and multiple shoot regeneration as compared to Solanum lycopersicum (Micro-Tom) (Fig. 1) while in stem node induction, Solanum lycopersicum (Micro-Tom) showed high axillary bud regeneration frequency over S.pimpinellifolium (WVa700) (Fig. 2 and Fig. 3).

Plants with a well-developed root system were moved to pots with a soil and perlite compound (3:1) and subsequently successfully acclimated and grown in a glasshouse. All in vitro plants were characterized by normal phenotypic appearance. 


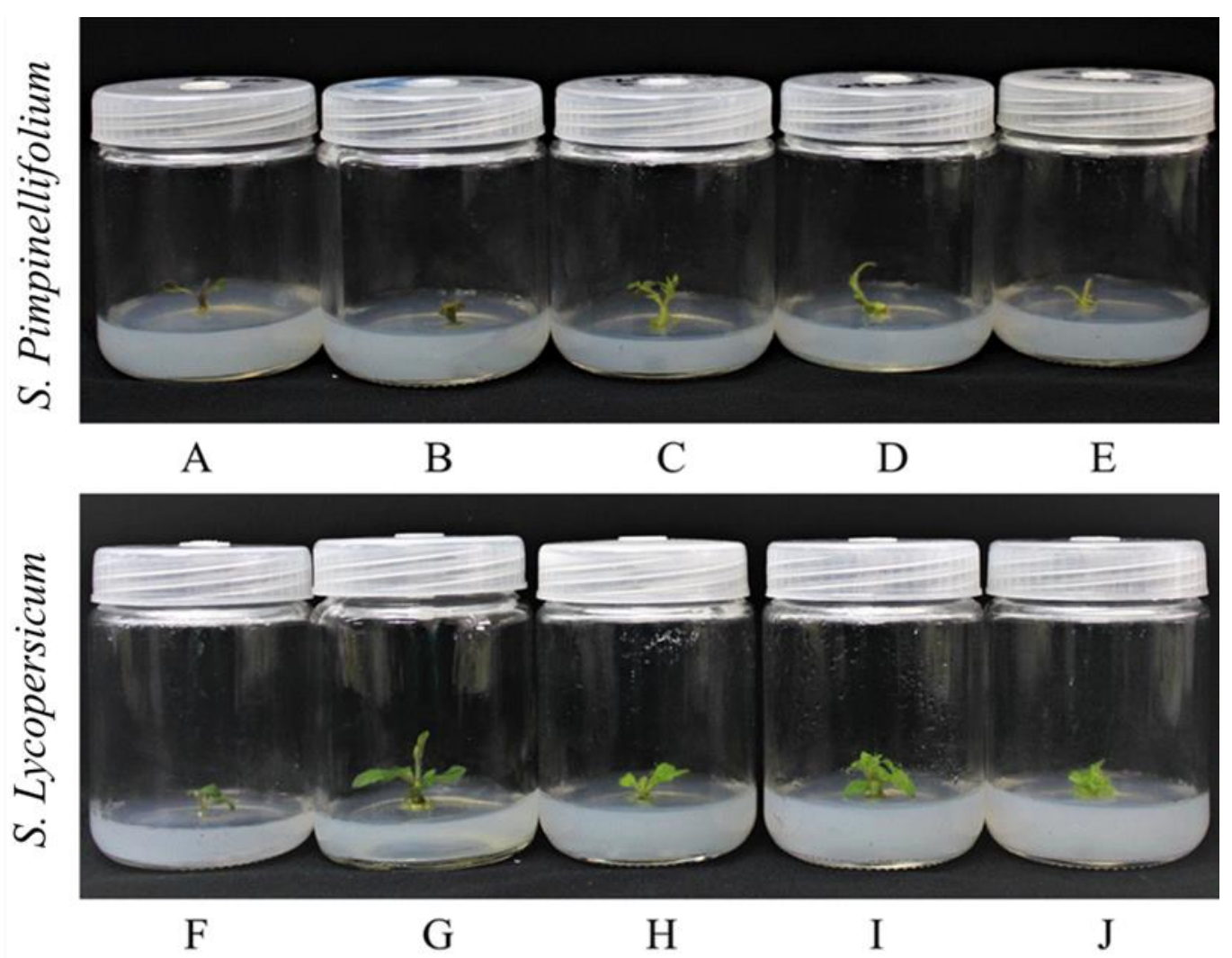

Figure 3. Axillary bud regeneration from stem node explant of Solanum lycopersicum $\mathrm{c} v$. Micro-Tom, S. pimpinellifolium line WVa700, A. control. B. $1 / 2 M S+1 B A, C .1 / 2 M S+3 B A, D .1 / 2$ $M S+5 B A, \boldsymbol{E} .1 / 2 M S+7 B A$ for S. pimpinellifolium (WVa700), $\boldsymbol{F}$. control, $\boldsymbol{G} .1 / 2 M S+7 B A, \boldsymbol{H} .1 / 2$ $M S+5 B A, I .1 / 2 M S+3 B A, \boldsymbol{J} .1 / 2 M S+1 B A$, for S.lycopersicum (Micro-Tom)

\section{Discussion}

The seeds of both cultivars Solanum lycopersicum and $S$. pimpinellifolium were germinated on plant growth regulator-free MS medium. Fifteen days after germination, seedlings were harvested for use as explant. The use of in vitro methods is useful for many cultivars and the individuals who rely on them. It has been noted that plant regeneration by in vitro technologies is usually associated with the existence of variability among regenerants (Duncan, 1996).

In our previous studies, phenotypic traits of parents and their hybrids in terms of plant height $(6.866 \mathrm{~cm}$ for M_W and $5.966 \mathrm{~cm}$ for W_M) at 6 leaf stage, plant height $(56.66 \mathrm{~cm}$ for M_W and $74.33 \mathrm{~cm}$ for W_M) at 8 leaf stage (70 days old leaf), fruit shape index (0.953 for M_W and 0.985 for W_M) and single fruit weight (3.622 g for M_W and $4.352 \mathrm{~g}$ for W_M) were observed at 6 leaf stage (45 days old leaf) respectively (Fig. 4 and Fig. 5) (Raza et al., 2017). The present experiment was performed to conserve $F_{1}$ generation used in our previous studies by using in vitro technique.

Plant growth regulators (PGRs); have influenced the morphogenic response by modifying various physiological processes. In the case of tomato regeneration, a broad range of different phytohormones (e.g. BAP, zeatin, 2iP (isopentenyl adenine), KIN (Kinetin), IAA, NAA ( $\alpha$ Naphthaleneacetic acid) IBA (Indole-3-butyric acid), 2, 4-D (2, 4-Dichlorophenoxyacetic acid) at varying concentrations have been used so far (Koleva Gudeva and Dedejski, 2012; Jehan and Hassanein, 2013; Koul et al., 2014). 

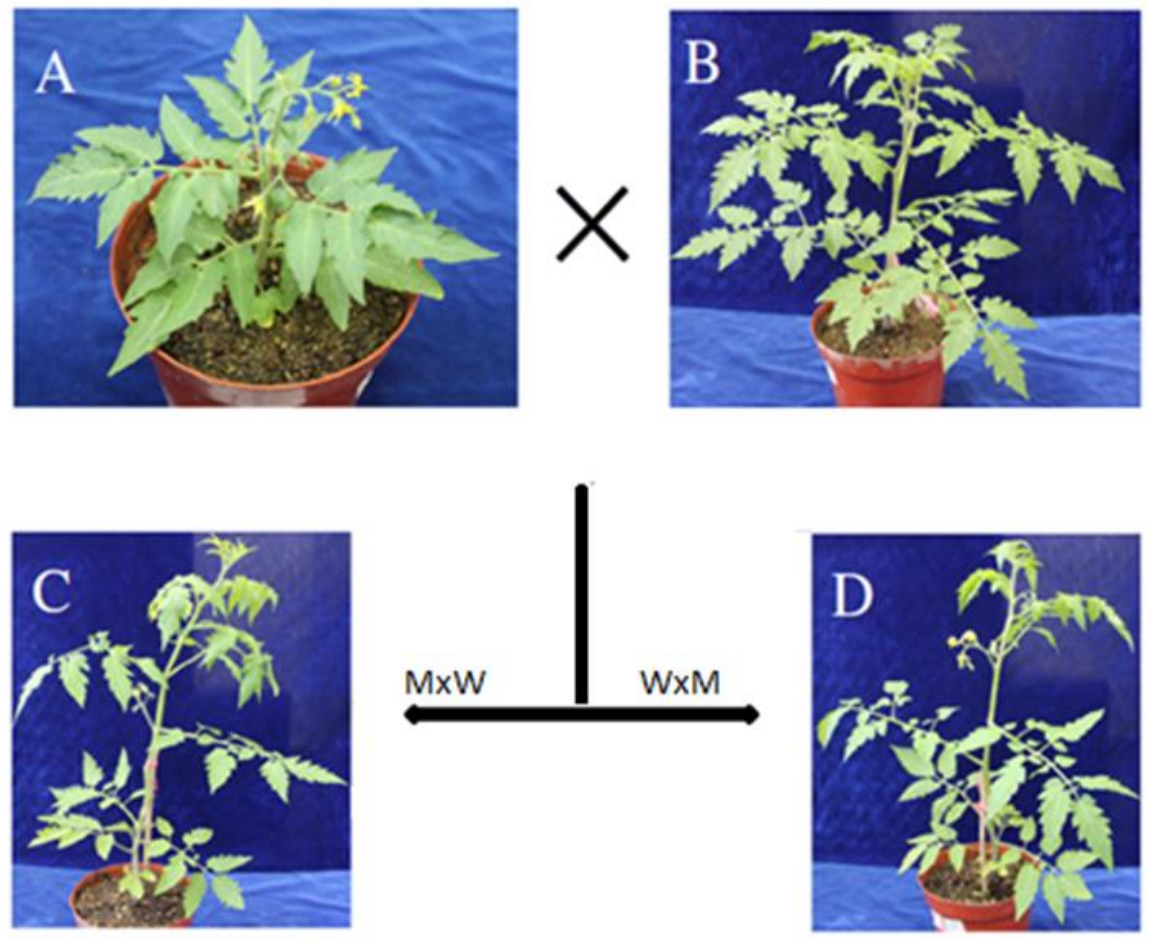

Figure 4. Parents and their reciprocal hybrids, A. Solanum lycopersicum cv. Micro-Tom, B. S. pimpinellifolium line WVa700, C. Micro-Tom_WVa700 i.e. (Micro-Tom X WVa700) D. WVa700_Micro-Tom i.e. (WVa700 X Micro-Tom)
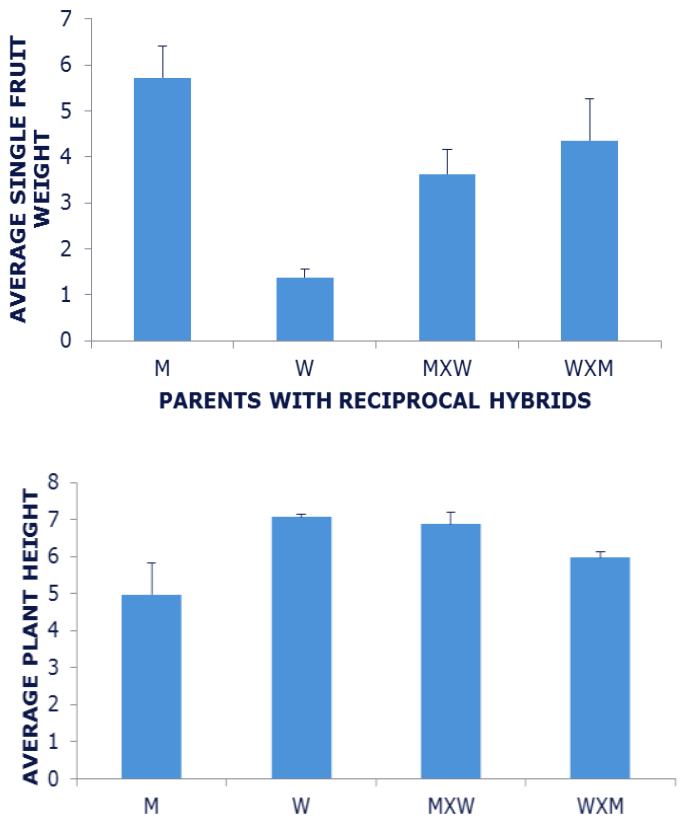

PARENTS AND RECIPROCAL HYBRIDS AT 6 LEAVES STAGE
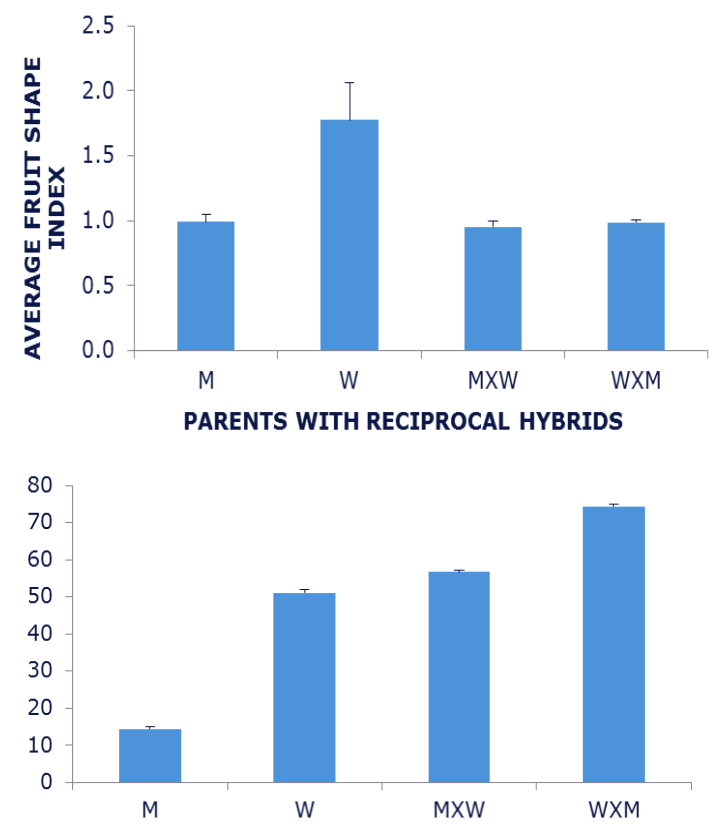

PARENSTS AND RECIPROCAL HYBRIDS AT 8 LEAVES STAGE

Figure 5. Phenotypic traits of parents Solanum lycopersicum cv. Micro-Tom, S. pimpinellifolium line WVa700, and their reciprocal hybrids (Micro-Tom X WVa700) and (WVa700 X Micro-Tom) 
Moreover, the nature and concentration of PGRs used in the medium proven to be dependent on the cultivar being cultured and especially on the auxin or cytokinins applied (Koleva Gudeva and Dedejski, 2012; Bahurupe et al., 2013; Jehan and Hassanein, 2013; Koul et al., 2014; Wayase and Shitole, 2014). Majority of in vitro methods depend on induction of the regeneration process exploiting different explants cultured in vitro. Various types of explants were used by others: seed-cut cotyledon, hypocotyl, leaf, stem sections, nods, internodes, pedicels, petioles, apical meristem, shoot apex/tip and inflorescences for organogenesis (Gerszberg et al., 2015).

A substantially higher range of BA $(22.2 \mu \mathrm{M})$ was used for Hedeoma multiflorum micro propagation (Koroch et al., 1997). Slightly lower values were recorded for S. lycopersicum (Micro-tom) (Fig. 1). In many tree species, a range of auxin in combination with cytokinin played a vital role in multiple shoot regeneration (Vengadesan et al., 2002; Giri et al., 2004; Anis et al., 2011). Moreover, addition of low levels of auxin along with cytokinin is known to increase shoot numbers in many plant species like Wrightia tinctoria (Purohit et al., 1994).

\section{Conclusion}

The present study revealed an acceptable frequency of regeneration from two explants (cotyledons and stem node segments). Development of an effective in vitro regeneration protocol for crop species could be extremely beneficial in the process of cultivating and creating new varieties or in breeding lines in a relatively short period of time and for genetic improvement by exploiting biotechnology strategies. It is known that there are more than ten thousand tomato cultivars, and it is therefore impossible to establish a universal tomato regeneration protocol.

Hence, creating a tissue culture protocol for selected commercially important varieties is fully justified. This step should be preceded by wide screening of the abovementioned varieties of morphogenic potential. Our study would provide novel valuable information about this very important issue. It can be concluded from the above findings that the regeneration protocol developed in this study is simple, reproducible and applicable.

Acknowledgements. The research was supported by Food Science and Engineering-the most important discipline of Zhejiang Province (No. 2017SIAR207) and Higher Education Commission of Pakistan (No: 21-1997/SRGP/ R\&D/HEC/ 2018).

\section{REFERENCES}

[1] Anis, M., Ahmad, N., Siddique, I., Varshney, A., Naz, R., Perveen, S., Khan, P. (2011): Biotechnological approaches for the conservation of some forest tree species. Forest decline: causes and impacts. - Nova Science Publishers Inc., New York, USA, 1-39.

[2] Bahurupe, J., Patil, S., Pawar, B., Chimote, V., Kale, A. (2013): Callus induction and plantlet regeneration in tomato (Solanum lycopersicum L.). - Journal of Cell and Tissue Research 13(2): 3765.

[3] Benson, E. E. (2000): Sepecial symposium: In vitro plant recalcitrance in vitro plant recalcitrance: An introduction. - In Vitro Cellular \& Developmental Biology-Plant 36(3): $141-148$. 
[4] Bhatia, P., Ashwath, N., Senaratna, T., Midmore, D. (2004): Tissue culture studies of tomato (Lycopersicon esculentum). - Plant cell, tissue and organ culture 78(1): 1-21.

[5] Duncan, R. (1996): Tissue culture-induced variation and crop improvement. - Advances in agronomy 58: 201-240.

[6] Gerszberg, A., Hnatuszko-Konka, K., Kowalczyk, T., Kononowicz, A. K. (2015): Tomato (Solanum lycopersicum L.) in the service of biotechnology. - Plant Cell, Tissue and Organ Culture (PCTOC) 120(3): 881-902.

[7] Giri, C., Shyamkumar, B., Anjaneyulu, C. (2004): Progress in tissue culture, genetic transformation and applications of biotechnology to trees: an overview. - Trees 18(2): 115-135.

[8] Gomez, K. A., Gomez, A. A. (1984): Statistical procedures for agricultural research. John Wiley \& Sons.

[9] Hanus-Fajerska, E. (2005): Variation in Tomato Plants Regenerated from Cucumber Mosaic Virus Infected Tissue. - Paper presented at the XV Meeting of the EUCARPIA Tomato Working Group 789.

[10] Ishag, S., Osman, M. G., Khalafalla, M. M. (2009): Effects of growth regulators, explant and genotype on shoot regeneration in tomato (Lycopersicon esculentum cv Omdurman). - Int J Sustain Crop Prod 4: 7-13.

[11] Jehan, S., Hassanein, A. (2013): Hormonal requirements trigger different organogenic pathways on tomato nodal explants. - American Journal of Plant Sciences 4(11): 2118.

[12] Khuong, T. T. H., Crété, P., Robaglia, C., Caffarri, S. (2013): Optimisation of tomato Micro-tom regeneration and selection on glufosinate/Basta and dependency of gene silencing on transgene copy number. - Plant cell reports 32(9): 1441-1454.

[13] Koleva Gudeva, L., Dedejski, G. (2012): In vivo and in vitro production of some genotypes of cherry tomato Solanum lycopersicum var. Cerasiforme (DUNAL). International Journal of Farming and Allied Science 1(4): 91-96.

[14] Koroch, A. R., Juliani, H. R. Jr., Juliani, H. R., Trippi, V. S. (1997): Micropropagation and acclimatization of Hedeoma multiflorum. - Plant cell, tissue and organ culture 48: 213-17.

[15] Koul, B., Srivastava, S., Amla, D., Sanyal, I. (2014): Establishment and optimization of agrobacterium-mediated transformation and regeneration of tomato (Solanum lycopersicum L.). - International Journal of Biosciences (IJB) 4(10): 51-69.

[16] Li, T., Sun, J. K., Lu, Z. H., Liu, Q. (2011): Transformation of HBsAg (Hepatitis B Surface Antigen). - Czech J. Genet. Plant Breed 47(2): 69-77.

[17] Namitha, K. K., Pradeep, S. N. (2013): Morphogenetic Potential of Tomato (Lycopersicon esculentum) cv.'Arka Ahuti' to Plant Growth Regulators. - Notulae Scientia Biologicae 5(2): 220.

[18] Purohit, S., Kukda, G., Sharma, P., Tak, K. (1994): In vitro propagation of an adult tree Wrightia tomentosa through enhanced axillary branching. - Plant Science 103(1): 67-72.

[19] Raiola, A., Rigano, M. M., Calafiore, R., Frusciante, L., Barone, A. (2014): Enhancing the health-promoting effects of tomato fruit for biofortified food. - Mediators of inflammation Vol. 2014: 139873.

[20] Rashid, R., Bal, S. S. (2010): Effect of hormones on direct shoot regeneration in hypocotyl explants of tomato. - Notulae Scientia Biologicae 2(1): 70.

[21] Raza, M. A., Yu, N., Wang, D., Cao, L., Gan, S., Chen, L. (2017): Differential DNA methylation and gene expression in reciprocal hybrids between Solanum lycopersicum and S. pimpinellifolium. - DNA Research 24: 597-607.

[22] Vengadesan, G., Ganapathi, A., Amutha, S., Selvaraj, N. (2002): In vitro propagation of Acacia species-a review. - Plant Science 163(4): 663-671.

[23] Wayase, U., Shitole, M. (2014): Effect of plant growth regulators on organogenesis in tomato (Lycopersicon esculentum Mill.) cv. Dhanashri. - International Journal of Pure and Applied Sciences and Technology 20(2): 65-71. 
[24] Yarra, R., He, S.-J., Abbagani, S., Ma, B., Bulle, M., Zhang, W.-K. (2012): Overexpression of a wheat $\mathrm{Na}+\mathrm{H}+$ antiporter gene (TaNHX2) enhances tolerance to salt stress in transgenic tomato plants (Solanum lycopersicum L.). - Plant Cell, Tissue and Organ Culture (PCTOC) 111(1): 49-57.

[25] Zhang, W., Hou, L., Zhao, H., Li, M. (2012): Factors affecting regeneration of tomato cotyledons. - Bioscience Methods, 3(4). 